\title{
Impact Of "eHealth" in Allergic Diseases and Allergic Patients
}

\author{
Alvarez-Perea $A^{1,2}$, Sánchez-García $S^{3,4}$, Muñoz Cano $R^{4,5,6}$, Antolín-Amérigo $D^{7,8}$, Tsilochristou $0^{9}$, \\ Stukus DR ${ }^{10}$
}

\author{
'Allergy Service, Hospital General Universitario Gregorio Marañón, Madrid, Spain \\ ${ }^{2}$ Gregorio Marañón Health Research Institute, Madrid, Spain \\ ${ }^{3}$ Allergy Unit, Hospital Infantil Universitario Niño Jesús, Madrid, Spain \\ ${ }^{4}$ Spanish Research Network on Allergy (ARADyAL: Red Nacional de Alergia-Asma, Reacciones Adversas y Alérgicas-) of the Carlos III Health \\ Institute, Madrid, Spain \\ ${ }^{5}$ Allergy Section, Pneumology Department, Hospital Clinic, University of Barcelona. Barcelona, Spain \\ ${ }^{6}$ Inmunoalergia Respiratoria Clinica y Experimental (IRCE), Institut d'Investigacions Biomediques August Pi i Sunyer (IDIBAPS), Barcelona, Spain \\ ${ }^{7}$ Allergy Department, Hospital Universitario Ramón y Cajal, Madrid, Spain \\ ${ }^{8}$ IRYCIS, Instituto Ramón y Cajal de Investigación Sanitaria, Madrid, Spain \\ ${ }^{9}$ Peter Gorer Department of Immunobiology, School of Immunology \& Microbial Sciences, King's College London, London, United Kingdom \\ ${ }^{10}$ Nationwide Children's Hospital and The Ohio State University College of Medicine, Columbus, Ohio, USA
}

J Investig Allergol Clin Immunol 2019; Vol. 29(2): 94-102

doi: 10.18176/jiaci.0354

\section{Abstract}

The emergence of new technology enables allergists and patients to compile data and receive feedback regarding key symptoms, risk behavior, and/or management. The term "eHealth" refers to a diverse group of tools that use computerized technologies to improve both the efficacy and the efficiency of the health care industry.

eHealth comprises a variety of technologies, as follows: mobile devices (mHealth) in medical care, including electronic diaries, wearable sensors, and adherence monitoring; health informatics (eg, electronic health records, computerized physician order entry, clinical decision support); telemedicine, which is the use of information and communication technologies for the management of diseases and medical education; social media platforms, and the analysis of information acquired through these platforms using "big data" technologies. In this review, we summarize the latest findings on the use of eHealth technology and the relevance of eHealth to allergic conditions.

Key words: Big data. eHealth. mHealth. Social media. Telemedicine.

\section{Resumen}

La aparición de nuevas tecnologías conlleva para los alergólogos y los pacientes la posibilidad de recopilar datos y recibir información directa sobre los síntomas clave de las enfermedades, los comportamientos de riesgo y/o su manejo. El término "eHealth", o salud electrónica, se refiere a un grupo diverso de herramientas que utilizan tecnologías informáticas para mejorar la eficacia y la eficiencia de la industria de la salud.

La "eHealth" comprende varias tecnologías, como el uso de dispositivos móviles aplicados a la salud ("mHealth"), incluyendo diarios electrónicos, sensores ponibles o monitorización de la adherencia terapéutica; la informática biomédica (por ejemplo, la historia clínica electrónica, la prescripción electrónica o los sistemas de ayuda a las decisiones clínicas); la telemedicina, que es el uso de las tecnologías de la información y la comunicación para el manejo de enfermedades y de educación sanitaria; las plataformas de redes sociales, y el análisis de la información adquirida a través de estas plataformas, usando técnicas de "big data" o inteligencia de datos.

En esta revisión, resumimos la evidencia que rodea al uso de tecnologías "eHealth" y su relevancia para las enfermedades alérgicas.

Palabras clave: Macrodatos. Salud electrónica. Salud móvil. Redes sociales. Telemedicina. 


\section{Introduction}

The meaning of "eHealth" (electronic health) has been a matter of debate for the last decade [1]. The most widely accepted explanation dates to 2001, when it was defined as "an emerging field in the intersection of medical informatics, public health and business, referring to health services and information delivered or enhanced through the Internet and related technologies. In a broader sense, the term characterizes not only a technical development, but also a state-of-mind, a way of thinking, an attitude, and a commitment for networked, global thinking, to improve health care locally, regionally, and worldwide by using information and communication technology" [2].

Regardless of an exact definition, the term eHealth, also known as medical informatics or health information technologies, covers a diverse group of tools that commonly utilize computerized technologies in order to improve the efficacy and efficiency of the health care industry (Figure 1) [3].

Adoption of new technologies is high among the general population in developed countries. In 2013, it was reported that $56 \%$ of adults in the United States owned a smartphone [4], while in 2016, 75\% of the European households had mobile internet access [5].

Allergic diseases are common chronic conditions that can have a lifelong impact. Allergies are estimated to affect up to $20 \%$ of the general population, and prevalence is growing, with recent recognition of an "allergy epidemic" [6]. Asthma, atopic dermatitis, and food allergies are entities that require successful implementation of self-management plans and patient empowerment to ensure the highest quality of life with the least interference in daily activities. Unfortunately, for many reasons, this is often difficult to achieve [7].

The availability of new technology grants both clinicians and patients the opportunity to compile data and receive feedback regarding key symptoms, risk behavior, and/or management. The implementation of smartphones and "apps" (applications), along with other electronic tools that can be applied to health care and a proper analysis of the data generated, can prove useful for improving routine management of allergic patients [8].

In this review, we summarize the latest findings on various eHealth platforms and their relevance to the specialty of allergy and immunology.

\section{mHealth}

Rapid technological advances over the past decade have been applied in health care at both individual and population level. Mobile health (mHealth) refers to the use of mobile devices (smartphones, sensors, wearable technology, telemedicine) in medical care. mHealth encompasses an evolving field of applications that will be discussed in more detail below. mHealth technology can be integrated into the management of virtually any chronic health condition, including asthma, food allergy, and allergic rhinitis, and has tremendous potential for improving care for patients across the world. The utility of mHealth varies widely, from simple electronic symptom diaries or reminder systems, to complex sensors that offer real-time biofeedback to patients and comprehensive clinical information to health care providers or third-party observers. Artificial intelligence can help decipher millions of data items collected through mHealth applications and assist providers and patients with medical decision-making. Technology has reached a point where the main barrier lies in the limitations of the human imagination.

Naturally, the technological advances and promises of future applications have outpaced our ability to fully understand the benefits and limitations, as well as the challenges that may prevent widespread implementation [9]. Evidence supporting meaningful clinical benefit from mHealth applications is generally lacking, although this has not prevented companies from developing or recommending use of their products. In general, studies evaluating the use of mHealth in the management of chronic conditions such as asthma and diabetes still offer low-quality design and outcome measures [10].

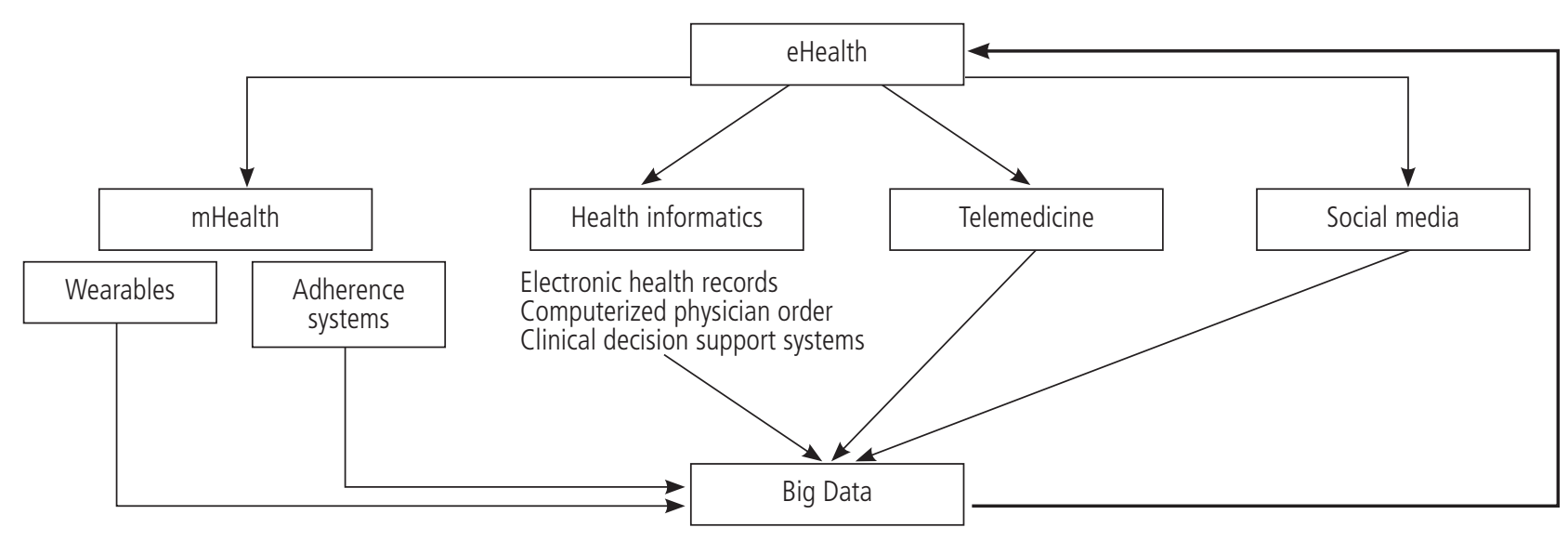

Figure 1. The term eHealth comprises various computerized tools, all of which can be used as a source of records for Big Data. Analysis of data would result in improved efficacy and efficiency of the system. 
Studies conducted in adult patients with asthma have revealed an improvement in symptom scores, increased attendance at office visits, and reduced visits to the emergency department for patients who have used a combination of home spirometry and simple message servicing [11,12]. A randomized prospective trial of mHealth applications in children with asthma did not demonstrate any difference in visits to the emergency department or hospitalizations over a 6-month period, although the number of visits to the emergency department decreased [13].

At the time of writing, there are over 300000 mHealth applications available for anyone to download and use. In 2013, the United States Food and Drug Administration decided that mHealth applications would not be regulated unless they are classified as a Class II or III medical device, which generally includes some form of sensor or adaptor measuring clinical information. Without oversight, the breadth of mHealth offerings can be overwhelming and unreliable. Many applications may not have been developed by health care experts or offer evidence-based information [14]. It is important for the entire health care industry, including practitioners, insurance providers, and especially patients, to understand these limitations and adopt mHealth with caution. More than ever, the marketing of such technology must be balanced with clinical utility. Equally important, patient privacy must be fully protected, particularly if mHealth applications are designed to transmit private medical information to providers.

\section{Wearables}

According to recent advances in nanotechnology and wireless communication, one of the new facilities technology offers is also one of the most commonly used: wearable biosensors aimed at providing vital signs and monitoring not only for patients, but also for athletes and the general population (Figure 2) [15].

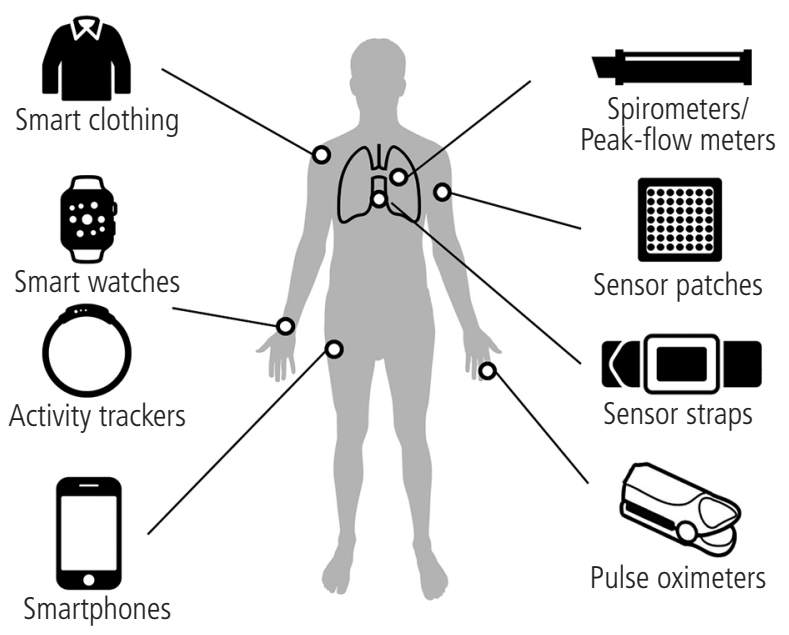

Figure 2. Available and potential sensors for use in wearables.
Although wearables have been applied for several health disorders [16], little is known about their use in allergic diseases. In asthma, a device for identifying wheeze integrates measurements from different stethoscopes into diagnostic algorithms that aid home diagnosis of asthma [17]. A lowpower device consisting of a wristband, a chest patch, and a hand-held spirometer has been developed to monitor multiple variables, including ozone levels, temperature, humidity, wheezing, and lung function. Its purpose is to improve management of chronic respiratory diseases such as asthma. However, clinical utility has not been demonstrated as of yet [18]. A commercially available wrist-worn device developed to monitor the sleep quality of children with asthma demonstrated favorable results, including adequate correlation with polysomnographic data [19].

Patients with food allergy and anaphylaxis could theoretically benefit from wearable technology. At least 2 projects are investigating anaphylaxis detection devices, which would act by measuring mast cell mediators; however, their actual utility remains to be established [20]. Several devices claim to be able to detect traces of offending foods in prepared meals, mainly gluten for celiac patients. In the case of food allergens, there is a patent for a food allergen detection method using molecularly imprinted polymers [21]. The patent is being used for the development of a device that would detect peanut, tree nut, fish, shellfish, wheat, egg, milk, and soy [22]. Unfortunately, at the time of writing, there is no published evidence supporting such claims. Lastly, a "smart" case for epinephrine autoinjectors that is linked to the user's smartphone can improve management of anaphylaxis and decrease patients' anxiety [23].

Overall, studies are scarce and lack strength of methodological design and use of relevant outcome measures. Errors in detection of data are common owing to unconscious bias when developers apply a standard behavior to a heterogeneous population. As such, researchers have the responsibility to detect inconsistencies in health apps and wearables [24].

\section{Adherence Systems}

Nonadherence is one area where mHealth may have the most potential to positively impact patient care [25]. It is well established that nonadherence is common among patients managing chronic medical conditions and takes many forms [26]. Patients with poorly controlled asthma often do not use their controller medications consistently or with the proper inhaler technique [27]. Patients with food allergies frequently do not have their epinephrine autoinjector available at all times and, even if it is available, fail to use it for treatment of anaphylaxis [28]. Nasal corticosteroid sprays are the most effective therapy for treatment of chronic rhinitis, yet many patients fail to use them consistently, thus minimizing the benefit [29].

There are several potential ways that mHealth platforms can improve adherence (Table 1). An important psychological aspect to consider is that individual response to various reminder systems can vary. Some people respond very well to a daily reminder or calendar approach to increase medication 
Table 1. mHealth Elements Designed to Improve Adherence

\begin{tabular}{|c|c|}
\hline Feature & Potential Benefit \\
\hline Reminder systems & $\begin{array}{l}\text { Assist patients who forget to take } \\
\text { medication consistently }\end{array}$ \\
\hline Point scoring/rewards & $\begin{array}{l}\text { Make use of the application more } \\
\text { fun and provide positive } \\
\text { reinforcement to the user }\end{array}$ \\
\hline Competition & $\begin{array}{l}\text { Link medication use/symptoms } \\
\text { with a social media platform that } \\
\text { allows comparison with other users }\end{array}$ \\
\hline Sleek appearance & $\begin{array}{l}\text { Well-designed apps make it easier } \\
\text { for users to navigate through all } \\
\text { features }\end{array}$ \\
\hline Feedback & $\begin{array}{l}\text { Weekly updates within the app or } \\
\text { through electronic messaging can } \\
\text { promote ongoing engagement }\end{array}$ \\
\hline Sensors & $\begin{array}{l}\text { Unique design element that can } \\
\text { provide reminders or reinforce } \\
\text { medication use }\end{array}$ \\
\hline Symptom diaries & $\begin{array}{l}\text { Encourages ongoing engagement } \\
\text { and potential for patients to review } \\
\text { their progress }\end{array}$ \\
\hline $\begin{array}{l}\text { GPS activity trackers } \\
\text { with environmental } \\
\text { alerts }\end{array}$ & $\begin{array}{l}\text { Offers real-time assessment/ } \\
\text { feedback for patients regarding air } \\
\text { quality or other environmental } \\
\text { factors as regards their exact location }\end{array}$ \\
\hline
\end{tabular}

use on a consistent basis. However, reminder systems and alarms can have unintended consequences, particularly for patients who are not coping well with their chronic medical condition and do not want a constant reminder of their reliance on medications [11].

The long-term commitment to using mHealth applications by patients is widely unknown. It is anticipated that most people will either lose interest or stop using their applications over time, unless they recognize the benefit and experience some positive reinforcement. Gamification uses elements found in game playing (point scoring, competition with others, unlocking rewards) as a way to increase user engagement. Variable reinforcement akin to playing slot machines can tie in with gamification to provide intermittent rewards to users. Ultimately, tangible rewards, eg, gift cards or reduced cost of medications, may offer the best approach to maintain user engagement although this requires financial support. If more studies can demonstrate the clinical efficacy of mHealth platforms, then insurance providers or third-party payers may be more willing to finance rewards, especially if clinically meaningful improvement and cost savings can be demonstrated, eg, reduced asthma-related emergency department visits.

The development of simple reminder systems or alarms includes the use of sensors on medication bottles or inhalers [30]. Sensors can be programmed to turn certain colors or emit a reminder sound when the bottle has not been opened or the inhaler has not been used at a prespecified time. The benefit of these sensors is that they provide a true picture of medication use, whereas reminder alarms/medication logs only record patient-reported use, but not actual use. An interesting aspect of sensors used in studies evaluating adherence with asthma inhalers demonstrates that patients enrolled in a clinical trial (and who know they are being monitored), self-report higher rates of adherence to medication compared with that detected by the sensor [31].

Ultimately, the most effective mHealth applications must include aspects designed to help improve patient adherence. However, we need to gain a better understanding of how the various approaches may not only impact adherence, but more importantly, know how they can be tailored towards individual patients. A one-size-fits-all approach will not likely be effective at the population level.

\section{Health Informatics}

Health informatics comprises a large number of other tools, including electronic health records, computerized physician order entry, clinical decision support systems, and additional software solutions for administrative tasks.

Digitalization of health care in general and allergy/ immunology in particular is expected to bring a number of benefits by improving quality, safety, efficiency, and costs. However, adapting new information systems to health care has proven difficult, and the scientific evidence supporting said effects is inconsistent [3,32].

Most studies addressing these effects have focused on clinical decision support systems and report beneficial effects [33]. For example, a study of electronic health record-embedded alerts performed in primary care pediatric centers resulted in a substantial improvement in asthma management [34]. However, other studies have reported these systems to result in "alert fatigue" and unnecessary workflows [33].

With respect to the cost- and efficiency-related benefits of health informatics, there is little to no evidence in the field of allergy. In general health care, results are controversial, with cost effects ranging from a $75 \%$ decrease to a $69 \%$ increase, after accounting for cost of implementation [32]. More quality studies on the costs of these systems are expected in the future.

\section{Telemedicine}

Telemedicine has several definitions. The World Health Organization (WHO) defines it as "the delivery of health care services, where distance is a critical factor, using information and communication technologies for the exchange of valid information for diagnosis, treatment and prevention of disease, research and evaluation, and for the continuing education of health care providers" [35]. There are 2 modalities of telemedicine: store-and-forward and real-time interactive services. In the first modality, packets of data (radiographic images, peak expiratory flow rate recordings) are transmitted to a specialist, who offers diagnostic or management advice. However, real-time interactive services involve real-time contact using information technologies (telephone, video calling) [36]. Telemedicine is used not only to exchange 
medical information between professionals, but also to remotely monitor patients with chronic conditions such as asthma, diabetes, and skin conditions, thus improving overall health outcomes [36,37].

Telemedicine has several potential benefits, including cost reduction [37] by reducing the number of cancelled appointments and travel to the hospital. A 2014 study found that e-visits could save as much as $\$ 5$ billion, considering that an e-visit costs approximately $\$ 40$ compared with an in-person visit which costs $\$ 73$ [37,38].

As for allergic conditions, telemedicine has been used mostly in patients with asthma. The first report was published by Romano et al [39], who found relief from symptoms and improved quality of life in 17 pediatric patients with asthma. Several studies subsequently demonstrated how monitoring peak flow using short message service (SMS) [40] or internetbased systems [41] and providing education to patients using face-to-face real-time telemedicine [42] improves asthma outcomes, proving to be comparable to in-person visits [43].

Another potential use of telemedicine is in triaging patients who require referral to the allergist for further evaluation. Krishna et al [36] proposed 4 triaging models for patients with allergic rhinitis, food allergy, chronic urticaria, and suspected anaphylaxis discharged from the emergency department. Finally, a recent study showed that telemedicine may be used to de-label penicillin-allergic patients, saving time and money (more than $\$ 30000$ ) and providing high satisfaction rates in patients [44].

Telemedicine has yet to be validated. Limitations, such as lack of physical evaluation, are obvious and of the utmost importance in respiratory diseases. Satisfaction with a telemedicine consultation for respiratory tract infections has been reported to be high. However, it has also been reported that antibiotics are often overprescribed to these patients, despite the fact that antibiotics are rarely warranted in the treatment of episodes. Moreover, patients who were prescribed antibiotics showed higher satisfaction rates $[45,46]$.

\section{Social Media}

The use of the internet in general and social media in particular as a source of health information has increased in recent years, as reported in several studies. A telephone survey conducted in the US in 2010 found that $15 \%$ of American adults use social media to gather health information [47]. A survey conducted by the European Commission in 2014 revealed that $59 \%$ of the respondents had used the internet to search for health-related information, while $17 \%$ searched for information regarding a specific disease on social media [48]. In 2015, a survey led by the Spanish Government demonstrated that $60.5 \%$ of adults use the internet for health-related purposes and $37.6 \%$ use social media in a similar fashion [49]. A recent study, based on a survey among food-allergic patients attending a Spanish pediatric allergy unit reported that over two thirds used social media, most of them daily, and that $25 \%$ used social media to gather information related to their disease [50].

However, few studies have evaluated the actual effect of social media and other similar online platforms in improving care for allergic conditions. Evidence supports a possible beneficial effect from use of these resources for patients with asthma [51,52]. A randomized clinical trial demonstrated that online reminders could increase asthma control among adults [53]. Yet, a paradoxical effect also seems possible [5456], given the ease with which incorrect and potentially harmful information may be accessed $[57,58]$.

One of the drawbacks of social media in allergy and other areas of health care is reliability. Only $14.7 \%$ of Spaniards consider social media a trustworthy source for health-related information [49]. There is no standardized method to measure the quality of information available in social networks [59]. In the particular case of allergy and immunology, reliability of videos posted on YouTube has been found to be low for asthma, rhinitis, and immunodeficiencies [60].

The growing trend in the use of social media also applies in physicians' private and professional aspects of life. A survey of Australian physicians found that $74 \%$ used social media networks to some extent [61]. From the point of view of allergists and clinical immunologists, social media seem to be a useful tool, which is not limited to sharing information, but can also be used for research [62], increasing the impact of scientific literature [63], and more [60]. In the last few years, the number of English-speaking allergists with Twitter accounts grew by $470 \%$ between 2011 and 2012 [64], and data from congresses in the USA [65] and Spain [66] show that their activity has been growing steadily.

Interestingly, $65.8 \%$ of Australian physicians indicated they were hesitant to immerse themselves more fully in social media and online communication owing to worries about public access and legal concerns [61]. Therefore, there is a clear need for guidance on the proper use of social media, which needs to be considered for all doctors that choose to be active in this realm. EAACI has recently updated their Code of Ethics by including an annex on social media use

Table 2. Tips Aimed at Understanding the Framework Underlying Social Media

- Social media is a method of building relationships with different parties (other doctors, members of the public, journalists, politicians and stakeholders) [87].

- Actions online and content posted may negatively affect reputations among patients and colleagues and can undermine public trust in the medical profession [88].

- Once content is online, it is extremely difficult to remove (if at all) and can thus quickly spread beyond one's control [89].

- Privacy settings do not guarantee that posts are not seen by a wider audience [67].

- The link between social media may blur the boundary between personal and professional identities [67].

- Interaction with patients within online public domains can be subjected to third-party scrutiny and misinterpretation [90].

- Anonymous patient specific information can still be linked to a specific patient. Optimal posts should include very general information [88].

- Defamers can be blocked and reported to the corresponding platform where the issue was raised. 
Table 3. Rules Aimed at Maintaining Digital Professionalism. Adapted From EAACI Code of Ethics [67]

- Distinguish private from professional presence and interaction online: create individual private and professional accounts. Ignore patients" "friendship requests" on private accounts: redirect them to professional accounts.

- Safeguard personal information and content: adjust privacy settings especially in relation to private social media accounts.

- Be conscious and cautious of one's online image. Selfidentify, including institution. Profile page should comply with the desired professional image.

- Maintain patients' confidentiality: do not disclose patients' information, avoid discussing complaints, do not acknowledge a physician-patient relationship online.

- Avoid providing specific medical advice online and encourage patients to address their health issues/concerns to an allergist in person.

- Adhere to updated institutional social media guidance that may apply in each individual case.

by allergists [67]. Tables 2 and 3 provide tips for allergists considering having a presence on social media. These tips may also help allergists navigate social media 'safely' should they decide to become active.

\section{Big Data}

The term "Big Data" refers to the recording and analysis of data sets which are so large, multidimensional, diverse, and complex that traditional software solutions are not adequate to process them [68]. The advent of Big Data is the result of the development of novel technologies that surpass the capacity of paper-based information management [69]. These technologies have enabled new ways to identify adverse events, cluster patients, and measure quality of care [70].

The application of Big Data to allergy and immunology research is resulting in the rapid transformation into a data-intensive discipline, as investigators are generating increasingly large, complex, multidimensional, and diverse data sets [71]. Sources of Big Data in health care include some of the technologies described previously in this article, such as mobile devices, websites, social media platforms, and wearables, although they also include genome registries, patient registries, private or government health claims, electronic health records, and pharmacy claims [72].

Given the complexity and heterogeneity of asthma and allergic diseases, a systems biology approach is attractive, as it has the potential to model the myriad connections and interdependencies between genetic predisposition, environmental perturbations, regulatory intermediaries, and molecular sequelae that ultimately lead to diverse disease phenotypes and treatment responses across individuals [73].

In systems biology, large data sets collected by multiple modalities in populations, ideally with multiple dimensions of data for each individual, are used to generate networks that link phenotyping information to interdependent genetic, regulatory, metabolic, and environmental profiles. The resulting networks are used to predict behavior of the trait and generate novel, biologically relevant information [74].

This approach is already being used to reach a better understanding of respiratory allergic diseases. The most common approach is to record data provided by patients, either actively or passively, via wearables. Asthma was one of the first conditions to be included in the ResearchKit platform (Apple), an open source framework for research that can be used to obtain informed consent, collect questionnaires, collect biometric data, provide reminders and notifications, and store data securely. The specially designed Asthma Health Application allowed a group of researchers to conduct the Asthma Mobile Health Study, which resulted in the collection of data from over 7000 American participants, 6000 of whom agreed to share their data publicly for further research [75] Initial analysis of this dataset revealed increased reporting of asthma symptoms in regions affected by heat, pollen, and wildfires [76].

Allergy Diary is a mobile phone application that collects data on allergic nasal, ocular, and asthma symptoms, as well as medication use, on a daily basis. During a 2-year-period, the developers included data from over 4000 patients totalling over 30000 days. Analysis of these data led to the description of a previously unrecognized pattern of uncontrolled multimorbidity $[77,78]$.

On the other hand, Big Data does not need to be based on data provided by patients. A model using Twitter, Google Search, and environmental sensors was able to predict the number of asthma emergency department visits in near real time with $70 \%$ accuracy [79]. Simple approaches, such as Google Trends searches of specific allergy-related queries, have proven useful for identifying the prevalence of allergic rhinitis symptoms in the European Union [80].

However, the ability to release, locate, integrate, and analyze data generated by others is subject to limitations [81] The use of the software associated with data is often restricted by the lack of tools, accessibility, and training. Improved statistical and mathematical models that can be integrated into patients' electronic medical records and tests that can be performed as point-of-care decisions are needed [82]. As the allergy/immunology field continues to evolve and mature, it is likely that these technologies will soon provide evidence-based decision support tools [83].

Finally, the proliferation of Big Data has already raised privacy concerns [84]. In the Big Data era, the notion of information ownership has blurred, because all the dataproducing actions (from social media to physician visits) involve more than 1 actor with inalienable rights to the data. For this reason, accepted norms on privacy will most probably change in the near future [85]. Still, the potential utility of big data and the uncertainty about the future must not be an excuse for not maintaining standards of ethical research [86].

\section{Conclusions}

Keeping up with ever-changing technology is of the utmost importance for allergy researchers and clinical 
practitioners. eHealth systems have been developing for over a decade. Nevertheless, it is in the last few years that it has become widespread. This is happening due to advances in miniaturization and the generalization of internet access. Application of these tools will undoubtedly affect the allergy field, for health care professionals and patients alike. Despite this generalization, there is a long way to go before we have solid evidence on the beneficial effects of these technologies. The quality of the evidence available for allergic diseases is still patchy and inconsistent.

We must not forget that allergic diseases have heterogeneous manifestations. For this reason, it is likely that what works for one disease may not work for the rest. Thus, it is important to ascertain what kind of intervention may be beneficial for each condition. In the same fashion, mHealth technologies and social media may have positive effects for a specific group of patients, but not for others. It will be important to identify which patients should be offered which options, along with clear expectations regarding benefits and risks.

One of the most important concerns of eHealth is privacy, which must be protected for all actors in health care, but especially for patients. Novel dynamics in data exchange, either for research or for clinical practice, must always be accompanied by the highest standards of privacy protection.

Finally, it is important to note that most eHealth studies have been performed in developed countries, where access to novel technology is cheap and common. However, given the significant lack of facilities and trained health care professionals in developing countries means that such areas of the world might benefit even more from these technologies.

\section{Funding}

Rosa Muñoz Cano is a recipient of a Juan Rodes fellowship (JR16/00016).

\section{Conflicts of Interest}

The authors declare that they have no conflicts of interest.

\section{References}

1. Boogerd EA, Arts T, Engelen LJ, van de Belt TH. 'What Is eHealth': Time for An Update? JMIR Res Protoc. 2015;4:e29.

2. Eysenbach G. What is e-health? J Med Internet Res. 2001;3:E20.

3. Chavannes NH, Du Puy RS, Bai C. Suggestions for health information technology trials for respiratory disorders in lowand middle-income country settings: what can we learn from trials in high-income country settings? NPJ Prim Care Respir Med. 2015;25:15045

4. Smith A. Smartphone Ownership 2013 [Internet]. Pew Res. Center's Available from: http://www.pewinternet. org/2013/06/05/smartphone-ownership-2013/ Accessed October 2, 2018.

5. European Commission. Special Eurobarometer 438 : E-Communications and the Digital Single Market. 2016. doi:10.2759/388948.

6. Matricardi P. The Allergy Epidemic. In: Akdis C, Agache I, editors. Global Atlas of Allergy. Zurich: EAACl 2014: 112-4.
7. Foster G, Taylor SJ, Eldridge S, Ramsay J, Griffiths CJ. Selfmanagement education programmes by lay leaders for people with chronic conditions. Cochrane Database Syst Rev. 2007; CD005108.

8. Marcano Belisario JS, Huckvale K, Greenfield G, Car J, Gunn LH. Smartphone and tablet self management apps for asthma. Cochrane Database Syst Rev. 2013;CD010013.

9. Steinhubl SR, Muse ED, Topol EJ. The emerging field of mobile health. Sci Transl Med. 2015;7:283rv3.

10. Marcolino MS, Oliveira JAQ, D'Agostino M, Ribeiro AL, Alkmim MBM, Novillo-Ortiz D. The Impact of mHealth Interventions: Systematic Review of Systematic Reviews. JMIR mHealth uHealth. 2018;6:e23.

11. de Jongh T, Gurol-Urganci I, Vodopivec-Jamsek V, Car J, Atun R. Mobile phone messaging for facilitating self-management of long-term illnesses. Cochrane Database Syst Rev. 2012;CD007459.

12. Beratarrechea $A$, Lee $A G$, Willner JM, Jahangir $E$, Ciapponi A, Rubinstein A. The Impact of Mobile Health Interventions on Chronic Disease Outcomes in Developing Countries: A Systematic Review. Telemed J e-Health. 2014;20:75.

13. Stukus DR, Farooqui N, Strothman K, Ryan K, Zhao S, Stevens $J \mathrm{H}$, et al. Real-world evaluation of a mobile health application in children with asthma. Ann Allergy Asthma Immunol. 2018;120:395-400.e1.

14. Huckvale K, Morrison C, Ouyang J, Ghaghda A, Car J. The evolution of mobile apps for asthma: an updated systematic assessment of content and tools. BMC Med. 2015;13:58.

15. Amft O. How Wearable Computing Is Shaping Digital Health. IEEE Pervasive Comput. 2018;17:92-8.

16. Ajami S, Teimouri F. Features and application of wearable biosensors in medical care. J Res Med Sci. 2015;20:1208-15.

17. Satat G, Ramchander K, Raskar R. Identi-wheez - A device for in-home diagnosis of asthma. In: 2016 38th Annual International Conference of the IEEE Engineering in Medicine and Biology Society (EMBC). IEEE. 2016: 4375-8.

18. Dieffenderfer J, Goodell H, Mills S, McKnight M, Yao S, Lin F, et al. Low-Power Wearable Systems for Continuous Monitoring of Environment and Health for Chronic Respiratory Disease. IEEE J Biomed Heal informatics. 2016;20:1251-64.

19. Sheth A, Yip $H$, Jaimini U, Sridharan V, Venkataramanan $R$, Thirunarayam K, et al. Feasibility Of Recording Sleep Quality And Sleep Duration Using Fitbit In Children With Asthma. Sleep. 2018;41:A297.

20. Puranik G, Petryk A. Wearables for Anaphylaxis [Internet]. Available from: https://scholarworks.bridgeport.edu/xmlui/ bitstream/handle/123456789/1931/673-final poster Gayathri_AP.pdf. Accessed October 2, 2018.

21. Barnes A, DelBruno J. Food Allergen Detection Methods and Systems Using Molecularly Imprinted Polymers. USA; US20160209420A1, 2016.

22. Allergy Amulet [Internet]. Available from: http://www. allergyamulet.com. Accessed October 2, 2018.

23. Cardona $V$, Luengo O, Labrador-Horrillo $M$, Moreno $N$, Guilarte M, Pala E, et al. First Clinical Trial with a Medical Device for Anaphylaxis Management. J Allergy Clin Immunol. 2018;141:AB149.

24. Brodie MA, Pliner EM, Ho A, Li K, Chen Z, Gandevia SC, et al. Big data vs accurate data in health research: Large-scale 
physical activity monitoring, smartphones, wearable devices and risk of unconscious bias. Med Hypotheses. 2018;119:326.

25. Haase J, Farris KB, Dorsch MP. Mobile Applications to Improve Medication Adherence. Telemed J E Health. 2017;23:75-9.

26. Lemstra M, Nwankwo C, Bird $Y$, Moraros J. Primary nonadherence to chronic disease medications: a metaanalysis. Patient Prefer Adherence. 2018;12:721-31.

27. Bender BG. Nonadherence to Asthma Treatment: Getting Unstuck. J Allergy Clin Immunol Pract. 2016;4:849-51.

28. Song TT, Worm M, Lieberman P. Anaphylaxis treatment: current barriers to adrenaline auto-injector use. Allergy. 2014;69:98391.

29. Ocak E, Acar B, Kocaöz D. Medical adherence to intranasal corticosteroids in adult patients. Braz J Otorhinolaryngol. 2017:83:558-62.

30. Barrett MA, Humblet O, Marcus JE, Henderson $K$, Smith T, Eid $\mathrm{N}$, et al. Effect of a mobile health, sensor-driven asthma management platform on asthma control. Ann Allergy Asthma Immunol. 2017;119:415-21.e1.

31. Krishnan JA, Bender BG, Wamboldt FS, Szefler SJ, Adkinson $N F$, Zeiger RS, et al. Adherence to inhaled corticosteroids: an ancillary study of the Childhood Asthma Management Program clinical trial. J Allergy Clin Immunol. 2012;129:1128.

32. Ammenwerth E. Evidence-based health informatics: How do we know what we know? Methods Inf Med. 2015:54:298307.

33. Jones SS, Rudin RS, Perry T, Shekelle PG. Health information technology: An updated systematic review with a focus on meaningful use. Ann Intern Med. 2014;160:48-54

34. Bell LM, R. G, Localio R, Zorc J, Fiks AG, Zhang X, et al. Electronic health record based decision support to improve Asthma care: A cluster-randomized trial. Pediatrics. 2010;125:e770-7.

35. WHO Group Consultation on Health Telematics (1997: Geneva, Switzerland). (1998). A health telematics policy in support of WHO's Health-for-all strategy for global health development : report of the WHO Group Consultation on Health Telematics, 11-16 December, Geneva, 1997. Geneva : World Health Organization.

36. Krishna MT, Knibb RC, Huissoon AP. Is there a role for telemedicine in adult allergy services? Clin Exp Allergy. 2016:46:668-77.

37. Elliott T, Shih J, Dinakar C, Portnoy J, Fineman S. American College of Allergy, Asthma \& Immunology Position Paper on the Use of Telemedicine for Allergists. Ann Allergy, Asthma Immunol. 2017;119:512-7.

38. Courneya PT, Palattao KJ, Gallagher JM. HealthPartners' Online Clinic For Simple Conditions Delivers Savings of $\$ 88$ Per Episode And High Patient Approval. Health Aff. 2013;32:38592.

39. Romano MJ, Hernandez J, Gaylor A, Howard S, Knox R. Improvement in asthma symptoms and quality of life in pediatric patients through specialty care delivered via telemedicine. Telemed J E Health. 2001;7:281-6.

40. Ostojic V, Cvoriscec B, Ostojic SB, Reznikoff D, StipicMarkovic A, Tudjman Z. Improving Asthma Control Through Telemedicine: A Study of Short-Message Service. Telemed e-Health. 2005;11:28-35.
41. Jan R-L, Wang J-Y, Huang M-C, Tseng S-M, Su H-J, Liu L-F. An internet-based interactive telemonitoring system for improving childhood asthma outcomes in Taiwan. Telemed J E Health. 2007:13:257-68.

42. Brown W, Odenthal D. The uses of telemedicine to improve asthma control. J Allergy Clin Immunol Pract. 2015;3:300-1.

43. Portnoy JM, Waller M, De Lurgio S, Dinakar C. Telemedicine is as effective as in-person visits for patients with asthma. Ann Allergy, Asthma Immunol. 2016;117:241-5.

44. Staicu ML, Holly AM, Conn KM, Ramsey A. The Use of Telemedicine for Penicillin Allergy Skin Testing. J allergy Clin Immunol Prac. 2018; In press. doi: 10.1002/14651858. CD005108.pub2.

45. Martinez KA, Rood M, Jhangiani N, Kou L, Boissy A, Rothberg MB. Association Between Antibiotic Prescribing for Respiratory Tract Infections and Patient Satisfaction in Direct-to-Consumer Telemedicine. JAMA Intern Med. 2018; In press. doi:10.1001/ jamainternmed.2018.4318.

46. Martinez KA, Rood M, Jhangiani N, Boissy A, Rothberg MB. Antibiotic Prescribing for Respiratory Tract Infections and Encounter Length: An Observational Study of Telemedicine. Ann Intern Med. 2018; In press. doi:10.7326/M18-2042

47. Fox S. The Social Life of Health Information, 2011 [Internet]. Available from: http://www.pewinternet.org/ /media//Files/ Reports/2011/PIP_HealthTopics.pdf. Accessed October 2, 2018.

48. European Commission. Flash Eurobarometer 404: European citizens' digital health literacy. 2014 doi:10.2759/86596.

49. ONTSI. Los Ciudadanos ante la e-Sanidad [Internet]. Available from: $\quad h$ ttp://www.ontsi.red.es/ontsi/sites/ontsi/files/los ciudadanos_ante_la_e-sanidad.pdf. Accessed October 2, 2018.

50. Alvarez-Perea A, Cabrera-Freitag P, Fuentes-Aparicio $V_{1}$ Infante S, Zapatero L, Zubeldia J. Social media as a tool for the management of food allergy in children. J Investig Allergol Clin Immunol. 2018:28:233-40.

51. Baptist AP, Thompson M, Grossman KS, Mohammed L, Sy A, Sanders GM. Social media, text messaging, and emailpreferences of asthma patients between 12 and 40 years old. J Asthma. 2011:48:824-30.

52. D'Amato G, Vitale C, Mormile M, Vatrella A, D'Amato M. The impact of social and digital media on asthmatic adolescents. Pediatr Allergy Immunol. 2016;27:650-1.

53. Pool AC, Kraschnewski JL, Poger JM, Smyth J, Stuckey HL, Craig TJ, et al. Impact of online patient reminders to improve asthma care: A randomized controlled trial. PLoS One. 2017; 12:e0170447

54. D'Amato G, Cecchi L, Liccardi G, Pellegrino F, Stanghellini G, Stanziala A, et al. Social networks and bronchial asthma. Curr Opin Allergy Clin Immunol. 2013;13:87-91.

55. D'Amato G, Cecchi L, Liccardi G, Pellegrino F, D'Amato M, Sofia M. Social networks: A new source of psychological stress or a way to enhance self-esteem? negative and positive implications in bronchial asthma. J Investig Allergol Clin Immunol. 2012;22:402-5.

56. D'amato $M$, Vitale $C$, Sanduzzi $A$, Stanziola $A$, Lanza $M$, Vatrella A, et al. Social networks, asthma and much more. J Investig Allergol Clin Immunol. 2015;25:445-7.

57. Rosenzweig D, Nickels AS. \#Asthma \#Inhaler: Evaluation of visual social media depictions of inhalers and spacers. J Allergy Clin Immunol Pract. 2017;5:1787-8. 
58. González-de-Olano D, Botella-Padilla I. Respiratory allergy buzz on the Internet. J Allergy Clin Immunol Pract. 2017;5:187-8.

59. Gabarron E, Fernandez-Luque L, Armayones M, Lau AY. Identifying Measures Used for Assessing Quality of YouTube Videos with Patient Health Information: A Review of Current Literature. Interact J Med Res. 2013;2:e6.

60. Dimov V, Eidelman F. Utilizing social networks, blogging and YouTube in allergy and immunology practices. Expert Rev Clin Immunol. 2015;11:1065-8.

61. Brown J, Ryan C, Harris A. How Doctors View and Use Social Media: A National Survey. J Med Internet Res. 2014;16:e267.

62. Sinnenberg L, Buttenheim AM, Padrez K, Mancheno C, Ungar L, Merchant RM. Twitter as a Tool for Health Research: A Systematic Review. Am J Public Health. 2017;107:e1-8.

63. Cosco TD. Medical journals, impact and social media: an ecological study of the Twittersphere. CMAJ. 2015;187:1353-7.

64. Dimov V, Gonzalez-Estrada A, Eidelman F. Social media and the allergy practice. Ann Allergy, Asthma Immunol. 2016;116:48490.

65. Stukus DR. Using Twitter to expand the reach and engagement of allergists. J Allergy Clin Immunol Pract. 2016;4:345-6.

66. Alvarez-Perea A, Ojeda P, Zubeldia JM. Trends in Twitter use during the Annual Meeting of the Spanish Society of Allergology and Clinical Immunology (2013-2016). J Allergy Clin Immunol Pract. 2018;6:310-2.

67. EAACI Code of Ethics [Internet]. Available from http://www. eaaci.org/images/committee_ethics/New-EAACl-Code-ofEthics-and-annexes.pdf. Accessed October 2, 2018.

68. Chen X-W, Gao JX. Big Data Bioinformatics. Methods. 2016;111:1-2.

69. Antolín-Amérigo D, Popescu FD, Alvarez-Perea A. Patientfriendly HIT tools and the advent of crowdsourcing clinical trials. In: Hellings PW, Agache I, editors. Implementing Precision Medicine in Best Practices of Chronic Airway Diseases. Elsevier. In press.

70. Wang Y, Kung L, Byrd TA. Big data analytics: Understanding its capabilities and potential benefits for healthcare organizations. Technol Forecast Soc Change. 2018;126:313.

71. Chaussabel D, Pulendran B. A vision and a prescription for big data-enabled medicine. Nat Immunol. 2015;16:435-9.

72. Raghupathi W, Raghupathi V. Big data analytics in healthcare: promise and potential. Heal Inf Sci Syst. 2014;2:3.

73. Bunyavanich S, Schadt EE. Systems biology of asthma and allergic diseases: A multiscale approach. J Allergy Clin Immunol. 2015;135:31-42.

74. Choi H, Song W-M, Zhang B. Linking childhood allergic asthma phenotypes with endotype through integrated systems biology: current evidence and research needs. Rev Environ Health. 2017;32:55-63.

75. Chan Y-FY, Bot BM, Zweig M, Tignor N, Ma W, Suver C, et al. The asthma mobile health study, smartphone data collected using ResearchKit. Sci Data. 2018;5:180096.

76. Chan Y-FY, Wang P, Rogers L, Tignor N, Zweig M, Hershman SG, et al. The Asthma Mobile Health Study, a large-scale clinical observational study using ResearchKit. Nat Biotechnol. 2017;35:354-62.

77. Bousquet J, Devillier P, Anto JM, Bewick M, Haahtela T, Arnavielhe $S$, et al. Daily allergic multimorbidity in rhinitis using mobile technology: A novel concept of the MASK study. Allergy. 2018;73:1622-31.

78. Bousquet J, Devillier P, Arnavielhe S, Bedbrook A, AlexisAlexandre $G$, van Eerd $M$, et al. Treatment of allergic rhinitis using mobile technology with real-world data: The MASK observational pilot study. Allergy. 2018;73:1763-74.

79. Ram S, Zhang W, Williams M, Pengetnze Y. Predicting AsthmaRelated Emergency Department Visits Using Big Data. IEEE J Biomed Heal Informatics. 2015;19:1216-23.

80. Bousquet J, Agache I, Anto JM, Bergmann KC, Bachert C, Annesi-Maesano I, et al. Google Trends terms reporting rhinitis and related topics differ in European countries. Allergy. 2017;72:1261-6.

81. Ehrenstein V, Nielsen $H$, Pedersen AB, Johnsen SP, Pedersen L. Clinical epidemiology in the era of big data: new opportunities, familiar challenges. Clin Epidemiol. 2017;9:245-50.

82. Auffray C, Balling R, Barroso I, Bencze L, Benson M, Bergeron $J$, et al. Making sense of big data in health research: Towards an EU action plan. Genome Med. 2016;8:71.

83. Bousquet J, Hellings PW, Agache I, Bedbrook A, Bachert C, Bergmann KC, et al. ARIA 2016: Care pathways implementing emerging technologies for predictive medicine in rhinitis and asthma across the life cycle. Clin Transl Allergy. 2016;6:47.

84. Mai J-E. Three Models of Privacy. New Perspectives on Informational Privacy. Nord Rev. 2016;37:171-5.

85. Mai J-E. Big data privacy: The datafication of personal information. Inf Soc. 2016;32:192-9.

86. Mooney SJ, Pejaver V. Big Data in Public Health: Terminology, Machine Learning, and Privacy. Annu Rev Public Health. 2018:39:95-112.

87. British Medical Association (BMA) Social media - practical guidance and best practice [Internet]. Available from https:// www.bma.org.uk/-/media/files/pdfs/employment advice/ ethics/social media guidance final.pdf. Accessed October 2, 2018.

88. American Medical Association (AMA) Policy: Professionalism in the Use of Social Media [Internet]. Available from: https:// mededu.jmir.org/article/downloadSuppFile/4886/28296. Accessed October 2, 2018.

89. Gholami-Kordkheili F, Wild V, Strech D. The impact of social media on medical professionalism: a systematic qualitative review of challenges and opportunities. J Med Internet Res. 2013;15:e184.

90. Hyman JL, Luks HJ, Sechrest R. Online professional networks for physicians: risk management. Clin Orthop Relat Res. 2012;470:1386-92.

\section{Manuscript received October 28, 2018; accepted for publication November 14, 2018.}

\section{- Alberto Alvarez-Perea}

Allergy Department

Hospital General Universitario Gregorio Marañón

E-mail: alberto@alvarezperea.com 